\title{
Inner transformation to sustainability as a deep leverage point: fostering new avenues for change through dialogue and reflection
}

\author{
Christoph Woiwode ${ }^{1,9} \cdot$ Niko Schäpke $^{2,10} \cdot$ Olivia Bina $^{3} \cdot$ Stella Veciana ${ }^{4,11} \cdot$ Iris Kunze $^{5} \cdot$ Oliver Parodi $^{6}$. \\ Petra Schweizer-Ries ${ }^{7} \cdot$ Christine Wamsler $^{8}$
}

Received: 30 December 2019 / Accepted: 9 November 2020 / Published online: 19 January 2021

(c) The Author(s) 2021

\begin{abstract}
This article provides a rationale for inner transformation as a key and hitherto underresearched dimension of sustainability transformations. Inner transformation relates to various aspects of human existence and interactions such as consciousness, mindsets, values, worldviews, beliefs, spirituality and human-nature connectedness. The article draws on Meadows' leverage points approach, as places to intervene in a system, to reveal the relevance of inner transformation for system change towards sustainability. Based on insights from a series of dialogue and reflection workshops and a literature review, this article provides three important contributions to sustainability transformations research: first, it increases our conceptual understanding of inner transformation and its relevance for sustainability; second, it outlines concrete elements of the inner transformationsustainability nexus in relation to leverage points; and third, it presents practical examples illustrating how to work with leverage points for supporting inner transformation. In sum, the paper develops a systematized and structured approach to understanding inner transformation, including the identification of deep, i.e., highly influential, leverage points. In addition, it critically discusses the often contentious and divergent perspectives on inner transformation and shows related practical challenges. Finally, current developments in inner transformation research as well as further research needs are identified.
\end{abstract}

Keywords Inner transformation · Deep leverage points · Paradigm shift · Mindsets · Consciousness · Values · Worldviews · Personal sustainability $\cdot$ Interiority $\cdot$ Personal spheres of transformation $\cdot$ Inner capacities $\cdot$ Human development

Handledby Daniel J. Lang, Leuphana University of Lueneburg, Faculty of Sustainability, Germany.

Electronic supplementary material The online version of this article (https://doi.org/10.1007/s11625-020-00882-y) contains supplementary material, which is available to authorized users.

Christoph Woiwode

woiwode@igcs-chennai.org

1 Visiting Faculty, Indo-German Centre for Sustainability at Indian Institute of Technology Madras, Chennai 600036, India

2 Division of Physical Resource Theory, Chalmers University of Technology, Gothenburg, Sweden

3 World Academy of Art and Science, Institute of Social Sciences, University of Lisbon, Lisbon, Portugal

4 Leuphana University, Lüneburg, Germany

5 Center for Global Change and Sustainability at the University of Natural Resources and Life Sciences, Vienna, Austria

6 Institute of Technology Assessment and Systems Analysis at the Karlsruhe Institute of Technology, Karlsruhe, Germany
7 Department Geography, University for Applied Sciences, Sustainability Science and Ruhr-University Bochum, Lennershof 140, 44801 Bochum, Germany

8 Lund University Centre for Sustainability Studies (LUCSUS), Box 170, 22100 Lund, Sweden

9 Department of Economic Geography, RWTH Aachen University, Aachen, Germany

10 Chair of Environmental Governance, Faculty of Environmental and Natural Resources, University of Freiburg, Tennenbacher Str. 4, 79106 Freiburg, Germany

11 Global Ecovillage Network Germany (GEN), Beetzendorf, Germany 


\section{Introduction and background}

There is growing understanding that the complex sustainability challenges of the twenty-first century cannot be resolved at merely the material, physical or technological planes (Adger et al. 2013; Hulme 2009; Ives et al. 2019; O'Brien 2018). This points to a need to widen the nature and range of pathways that are considered to secure more sustainable futures.

Consequently both, scholars and practitioners increasingly highlight that the techno-scientific (outward) focus of sustainability transformations and transitions needs to be complemented with psychological, cultural, artistic and spiritual dimensions of human life (inward focus) and its future possibilities (see, e.g., EEA 2016, Geels and Schott 2007; Hunecke 2018, Köhler et al. 2019; Leal Filho and Consorte McCrea 2019, Upham et al. 2019). In this context, inner dimensions like consciousness, values, worldviews, beliefs, spirituality and human-nature-connectedness are seen as inevitably important for sustainability transformation at both the individual and societal plane (e.g., Hedlund-de Witt et al. 2014; Horcea-Milcu et al. 2019; Ives and Kidwell 2019; Wamsler et al. 2018). They are sometimes also described under the umbrella term 'mindsets' (Wamsler 2020,2018a, b). At policy level, the failure of informationbased approaches has shown the need for deeper and more long-term change. At the local level, civil society movements, faith communities, intentional communities and transition town initiatives have been experimenting with and applying inner transformation approaches. They do so as part of their own everyday efforts towards transitioning to more sustainable lifestyles at small scales (Kunze 2012; Kunze and Avelino 2015; Seyfang and Smith 2007; Veciana and Ottmar 2018). ${ }^{1}$

In sustainability transitions research, the urgent need for addressing inner dimensions has been acknowledged. Scholars highlight that "social nudge, regulatory shaping, and economic incentives are not in themselves sufficient to produce [the kinds of] transformational behavioral change" (O'Riordan and Lenton 2013: 316, cf. Schäpke 2018). Futurists point to similar concerns, stating that our current "external focus has tended to blind us to the shaping power of interior factors" (Slaughter 2012: 122). Scholars exploring the economic drivers of our crises also point towards a neglect of the deepest leverage points, intents and paradigms (Göpel 2016; Raworth 2017).

The emerging field of inner dimensions and transformation shares significant overlaps with the concept of 'leverage points' developed by Meadows (1999, 2008; cf. Abson et al. 2016, Fischer and Riechers 2019). Leverage points are conceptualized as places to intervene in a system with potentially increasing levels of impact towards system change (see Fig. 1). Shallow leverage points relate to material aspects of systems such as incentives and resource flows, as well as feedback-loops between them. Deeper leverage points include the structuring elements of systems, its rules and institutions, and even deeper leverage points include the

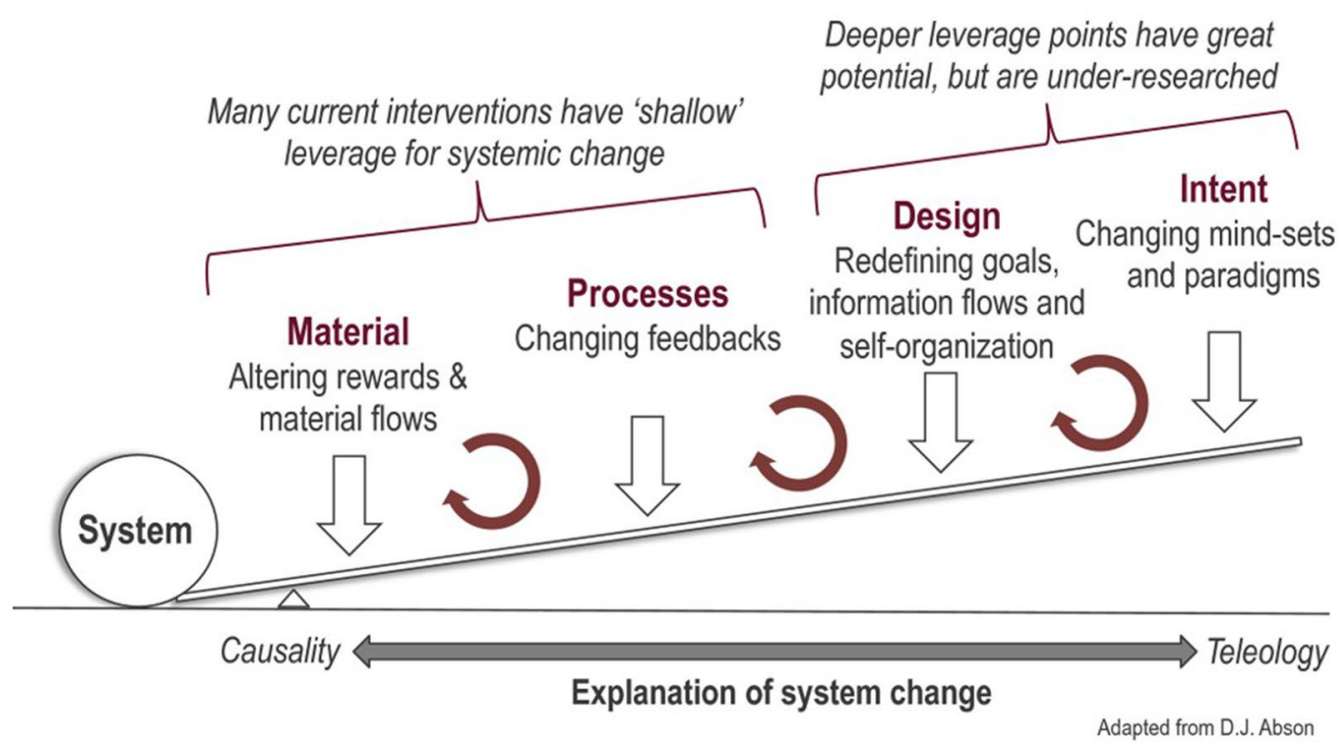

Fig. 1 Schematic illustration of four realms of leverage showing a gradient from shallow leverage points to deep leverage points (Source: Fischer and Riechers 2019, based on Abson et al. 2017, adapted from an ealier version of D.j. Abson)

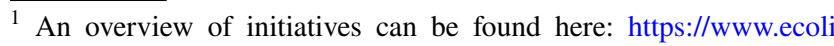
se.eu.
} 
design, intents and paradigms (or mindsets) underlying how systems are set up. Inner transformation thus strongly relates to deep(er) leverage points.

Despite the described needs and potential of inner transformation for sustainability, related research warrants further investigation (Fischer and Riechers 2019; Wamsler 2020; Ives et al. 2019). In this context, the possibilities of intentionally addressing inner dimensions as deep leverage points requires particular attention (Manfredo et al. 2017).

This article builds on the assumption that the combination of the leverage points concept and the emerging field of inner dimensions and transformation offers high potential to be mutually beneficial. Consequently, we aim to make three contributions: first, to increase our conceptual understanding of inner transformation and its relevance for sustainability (Sect. "Inner transformation and its relevance for sustainability"); second, to outline concrete elements of the inner-transformation-sustainability nexus in relation to deep leverage points (Sect. "The inner transformation-sustainability-nexus: Towards deep leverage points for system change"); and third, to present practical examples illustrating how to work with deep leverage points for inner transformation (Sect. "Addressing leverage points of inner transformations in practice"). Finally, we discuss related outcomes and present our conclusions (Sect. "Discussion and conclusions").

\section{Approach and methods}

In this study, we explore the potential of inner transformation as deep leverage point.

The article is based on a three-step methodology:

The first step involved the systematization of the outcomes of four dialogue and reflection sessions held at three conferences on Sustainability Transitions and Transformations ${ }^{2}$ in order to get an overview of current knowledge, approaches and practice. The sessions aimed to foreground concepts, approaches, empirical examples as well as practices of inner transformation work in relation to sustainability and to critically explore them by promoting dialogue among the participants. Each session brought together between 20 and 40 scholars and practitioners primarily from Europe. Participants represented a wide range of disciplines such as sociology, psychology, anthropology, urban planning, philosophy, physics, engineering, ecology, environmental studies, sustainability science and theology. Participants contributed conceptual and empirical, as well as practical expertise on the topic. The sessions combined different methods to elicit expertise, facilitate collective

\footnotetext{
${ }^{2}$ Conferences included the International Sustainability Transitions Conference 2016 and 2017, and the Leverage Points conference 2019 (with 2 sessions).
}

exploration as well as critical reflection. Methods ranged from expert inputs to group dialogues (e.g., world cafés, plenaries, fish-bowl discussions) to various individual and group reflection exercises (such as collective 'harvesting' and guided meditations). All sessions were documented in form of report minutes, visual group work outcomes, and/ or audio recordings (see Electronic Supplementary Materials-ESM S1, S2). The authors acted as initiators and session hosts, and participated in two or more sessions, often in facilitating roles.

During the second step, the information from the dialogue sessions was synthesized regarding the following three questions:

1. What is inner transformation and why is it relevant in the context of sustainability?

2. How can the contribution of inner dimensions and transformation to sustainability be conceptually understood in relation to deep leverage points?

3. What are good practice examples of working towards inner transformation?

The three research questions are broadly in line with the questions that were discussed during the dialogue and reflection sessions (see ESM S1, S2). Together, they formed the basis for an inductive approach to our conceptualization of inner transformation in relation to sustainability. Leverage points were raised as one of the important possible frameworks addressing change, at the third and fourth sessions, and proved powerful to synthesize insights. The themes, concepts, and discourses derived from the sessions were analyzed to explore the nexus between inner transformation and sustainability and how its various elements relate to the concept of leverage points. This analysis also involved the comparison to current literature on the issues. More specifically, we conducted thematic clustering of the information from the dialogue sessions by keywords and their relationships/ connections to other themes and concepts. The clustering was guided and structured based on the three guiding questions and in relation to the leverage points framework. The methodological steps two and three were thus conducted in parallel.

During the third step, synthesized insights from the sessions were embedded and discussed in relation to existing literature. The aim was to reflect the diversity of session contributions, based on individual author's and conference participant's professional focus, expertise and personal experiences, while seeking to develop a shared understanding and overarching perspective. 
In line with the ethos of our approach and material, we as authors use first person language to acknowledge subjectivity and the authenticity of experiential and empirical knowledge. This is also expressed by the critical, dialogical, discursive and reflective style congruent with the topic. Being both seekers of meaning and meaning makers in this process, our analyses are intersected by emerging new questions, refraining from providing conclusive answers.

Alongside the conference sessions, an 'Inner Transformation to Sustainability' group was created to facilitate exchange between researchers and practitioners, which has contributed to the discussions presented in this article. The authors of this article form part of this growing network and community of practice. It aims to advance research and practice on inner transformation, through action-oriented, transdisciplinary research, and to build knowledge and shared understanding on how to work with deep leverage points for sustainability transformations.

\section{Inner transformation and its relevance for sustainability}

This section explores main themes and concepts related to inner transformation that were discussed during the conference sessions and interweaves them with the emerging academic literature on the issue.

Whilst different definitions exist, a common denominator is that inner transformation relates to exploring and addressing people's inner dimensions and their relation to sustainability to support individual, collective and systems change. Based on their professional and academic work, several session participants argued that fundamental change towards sustainability can only succeed through transformation processes that also address inner dimensions at personal and collective levels. In this view, inner transformation is an inevitable part of the Great Transformation from fossil unsustainability to post-fossil sustainable development (WBGU 2011). The question 'who and what does actually have to change?' was vividly discussed by participants. How can we understand concepts related to inner dimensions and transformation (e.g., mindsets, consciousness, self and awareness), and what are the theories and fields of practice that are being applied in relation to these different concepts?

Participants considered inner transformation as a kind of re-orientation of who we are, i.e., as an existential concern. There are different notions of such 'inner change', which some argued may include a transcendental dimension. Participants considered it crucial to unpack the various aspects and layers of such change in order to get a better grasp of the inner transformation concept (e.g., people's values; personal and spiritual growth by way of compassion, empathy, or connectedness; patterns of behavior or attitudes). At the same time, as several participants argued, the diversity of these concepts, their understanding and origin (e.g., disciplinary, cultural) should be acknowledged. ${ }^{3}$ Diversity would include various possible subjects of inner transformation (the 'who'), including researchers, practitioners, or 'people' in the broadest sense. This involves a reflection on our own, personal view on inner development and transformation.

In line with the session participants, scholars tend to portray inner transformation as being concerned with the development, growth, and evolution of our 'inner Being' and 'Inner Presence' as part of our physical, materialized, embodied existence (Ulluwishewa 2014). Our Inner Being is a complex, multilayered construct. While humans hold a certain level of awareness on their Inner Being, constant reflection and awareness practice can unravel and enhance this understanding of the innermost source of our self $^{4}$ (Dev 2018). Personal sustainability (Horlings 2015; Parodi and Tamm 2018) and personal spheres of transformation (O'Brien and Sygna 2013) are two terms that have been used to describe inner transformation in relation to sustainable development. However, the individual, collective, and thus the cultural are interdependent dimensions of inner transformation processes, which cannot be seen in isolation (Horlings 2015).

This understanding emphasizes the need for the evolution of consciousness through development of a wider perspective and increasing consideration of complexity (Scharmer 2009). This development is described as a move from the self towards the Self, ${ }^{5}$ or progressing from ego-system to eco-system awareness (Scharmer and Kaufer 2015). Similarly, other scholars differentiate

\footnotetext{
3 The book 'Personal Sustainability' (Parodi and Tamm 2018) provides an overview and a first synopsis of the different core concepts and perspectives.

4 This expression is based on a particular ontology of the human being and relates to the notion that humans do have a multi-tiered inner reality. To reach down into one's inner source (Scharmer's term, 2009) requires unravelling various layers of one's personality (or self). This is a common concept in transpersonal psychology (e.g., Wilber's (2000) integral theory or Bhaskar's (2002b) multi-planar concept of the person), and eastern conceptions of 'man' (found across Hinduism, Buddhism, Taoism) (see also Combs 1996).

5 Scharmer and Kaufer (2015) provide a particular, encompassing ontology here: Self is understood as the universal self, embracing and acknowledging interdependence of all beings and the universe. In other words, recognizing the unity of existence.
} 
developmental stages to evolve in terms of individually and collectively held worldviews such as from egocentric, to ethnocentric, worldcentric, and kosmocentric worldviews (Wilber 2007). This view acknowledges the interrelation of the self and societal change, of self-development and socio-cultural transformation in sustainable development (e.g., Hochachka 2005).

The call for more emphasis on the role of inner transformation is inherent in the multidisciplinary field of environmental humanities, emanating from eco-theology, literature studies, ecofeminism, religious studies and the arts (e.g., Leal Filho and Consorte McCrea 2019; Rigby 2017). Environmental humanities highlight the relevance of culturally conditioned meanings, symbols, perceptions, values, ethics and worldviews for sustainable human/non-human relationships. Therefore, scholars from different disciplinary backgrounds increasingly argue that the current multiple crises are due to an alienation from ourselves, others, and the natural world (Bhaskar 2002a). Accordingly, reconnecting to our inner dimensions such as self-awareness, pro-social values or human-nature-connectedness is one way of overcoming this alienation, and subsequently the existing external crises.

This understanding links to Meadows (1999), stating that the deepest leverage points are the power to question and possibly transcend existing paradigms (or mindsets). Being a normative term, 'sustainability' was repeatedly challenged during the conference sessions because of its multilayered, multidimensional and context-dependent nature. While it has become a global development paradigm, critics argue that it is mostly used to fit existing pathways within the growth paradigm, whereas competing paradigms such as growth-critical, local or indigenous models are neglected (cf. Martínez-Allier et al. 2010). In this context, while some participants argued for a declining relevance of the concept which should be replaced, others noted that certain developments and policies, such as the Sustainable Development Goals, have given it 'new life' and potential. Constantly challenging concepts and ideas of sustainability are in fact key to the field itself (e.g., Jackson 2009, Leach et al. 2013, Raworth 2017, Rockström et al. 2009, Blythe et al. 2018). This is also true in relation to inner dimensions and transformation.
Do we change the existing understandings of sustainability, or do we invent a new paradigmatic 'reality'?

Session participants argued for the urgent need of a paradigm shift in thinking to prevent catastrophic system change and to reorient development towards sustainable futures. At the same time, approaches to change and associated public discourse need to be considered. Is it more relevant to influence predominating discourses or spur something new 'out at the margins'? One way of resolving this dilemma may be to use language strategically by following a two-pronged approach; that is, to use the term 'sustainability' to enter and connect with the 'mainstream' discourse, but to use a more 'radical' provocative terminology to critically reflect sustainability. This discussion relates to notions of a post-development era (Kothari et al. 2019), degrowth (D’Alisa et al. 2014) and deep adaptation (Bendell 2018) as examples of new paradigms that link to inner dimensions and transformation and that challenge predominant development pathways. They could allow to highlight new dimensions, stir up the academically preconditioned ways of thinking and attitudes, and stress the urgency for deep, profound, transformative change. As discussed in one session, radicality often reflects frustration with existing paradigms, and strives to enable and push for the emergence of new pathways. For instance, civil society movements such as Extinction Rebellion and Fridays for Future combine radical narratives and political action (ESM S2).

One aim of further exploring the role of inner dimensions for transformation is to critically reflect and widen the nature of pathways towards sustainability that are considered. In this context, religion and spirituality were repeatedly debated during the conference sessions since they shape people's and society's values, ethics and worldviews. In addition, scholars have noted the emergence of new paradigms, including a new spirituality (Heelas and Woodhead 2005; Knoblauch 2009), 'religious hybrids' (Berger et al. 2013), inter-religious dialogue (Lockhart 2011) and postsecularism (Habermas 2001). In this context, the notion of 'spirituality' can be seen as part of people's inner dimensions being rooted in a specific religious or non-religious understanding and/or practice of personal growth and transformation (Bucher 2007), which may be used to critically reflect, challenge and expand mainstream understandings of sustainability (Box $1^{6}$ ).

\footnotetext{
${ }^{6}$ As this topic remained contested during sessions and to provide an account of the different viewpoints, we present the discussion including participants' statements in a box complementing the main argumentation line. See as well Box 2, for another important yet contested discussion topic.
} 


\section{Box 1 - Session reflections: Instrumentalization of spirituality for inner} transformation? (see ESM S1, IST Conference 2016)

Inner transformation should not be seen as a vehicle of change. For many people, their personal inner world and related spiritual practice (e.g. prayer, meditation, contemplation, fasting, studying of spiritual texts) plays an important part of every-day life and their understanding of sustainability. This goes beyond formal religion. Session participants highlighted the risk and problematic tendency of instrumentalizing spirituality by reducing it to a mere tool for sustainability. As one participant commented:

"We can do trainings, like in the transition movement, but...Google does it as well, and many others corporations. Here we must be very cautious, you may use practices of meditation of different traditions and other practices for everything, e.g. to become personally stronger and financially more successful. While this might be worthwhile and important, we should also be aware that if we bring this into our transformation issues, it is tricky" .

Instrumentalizing spiritual practice to designing pro-active leverage points in the context of sustainability transformations might lead to superficial practices. It was argued that instrumentalization attempts reflect a paradigm of simple causality, of linear cause and effect, which is not shared by many spiritual traditions and is as well not applicable to solving complex, wicked problems. Such reductionist approach would also correspond to dominant western approaches to time and problem-solving. One participant remarked that we live in a world in which we want everything to happen fast by dividing systems in pieces and addressing them in isolation instead of addressing them comprehensively. This concern is shared by recent studies (e.g. Wamsler et al. 2020), highlighting the need to support inner transformative skills (intead of focusing on actual, simplistic solutions).

Countering the previous argument, another session participant said that instrumentalization of meditation is not really an issue, because the process of meditation facilitates for instance one's inner experience of perceiving oneself as part of a bigger whole. As one becomes aware of that whole, one will also be able to critically reflect associated sustainability problems. Several stressed that it would be an inherent part of inner practice to search for wider change. Accordingly, spirituality can be understood as one potential dimension of sustainability (transformation), but not as a vehicle for sustainability.

Literature on the link and relationship between sustainability and spirituality has been growing constantly (e.g., Gardner 2002, Dhiman 2016, Ulluwishewa 2014, Rauschmayer 2019). Spiritual practices are viewed both as inspiration and potential resources for 'The Great Transformation'. There is hardly an eco-social movement without any religious or spiritual underpinnings (Ott and Sachs 2016). In fact, many movements are indirectly influenced by religiously or spiritually oriented individuals like Mahatma Gandhi (Hinduism), E.F. Schumacher (Buddhist economics), or Thich Nhat Hanh (Buddhist). This phenomenon is expressed by terms, such as 'engaged Buddhism', 'practical spirituality' or 'green yoga' (Feuerstein and Feuerstein 2007; Woiwode and Woiwode 2019). It puts an emphasis on "transformative practice which leads to self-transformation, cultural 
transformation" (Giri 2018: 14) and transformation of the physical world (see Box 1 for a critical reflection).

Conference sessions did also explore extensively the relation of inner transformation and physical systems change; that is, the connectedness and influence between interiority and exteriority. Participants argued for a directional impetus of influence from the inner dimensions of our life world towards the exterior aspects of the material, outside world. For example, in the Transition Movement the inner and the outer aspects are not viewed separately:
'We assume that what we see in the outside is a reflection of the inside, which also means that we are one with our environment' (Gräff at IST Conference 2016, see ESM S1). Consequently, the relationship of inner and outer transformation would be about inner and outer integration of both the physical and subtle realities of the world, something which has been controversially debated during all conference sessions (see for example Box 2).

Box 2 - Session reflections: Inner Transformation, Human Agency and 'In-Action' - a paradox? (based on ESM S2, Leverage Points Conference 2019 session)

How do inner and outer realms of transformation relate to one another was a returning topic during the sessions, that is: where to focus human agency? In order to achieve inner transformation and, as some participants argued, subsequently, outer change, do we have to do 'nothing', be 'inactive', i.e. create a void first? As one participant remarked:

"...if we look at Buddhism, it would say 'if you want to relate to yourself, do nothing; if you want to relate to everything around you, do nothing'. We kind of go the other way around, we try to innovate social technology first, which you can then use to empower other people. We are creating new power relations between experts and non-experts. I think this is really difficult, or even dangerous. In my understanding it is more about creating space so that there is more emergence of connecting and re-connecting. Basically, instead of trying to fill this void, or the space that could be filled with new technology, think about how we can create space with this 'nothing' and see what connections might emerge" (Participant at IST 2016 session, see ESM S1).

From this perspective, the 'void' may be interpreted as creating a (safe) space for 'things to emerge' without exactly knowing what will happen. In this context, session discussions identified an inherent tension between sustainability and inner transformation, since sustainability is normative and generally defined by specific goals, e.g. the Sustainable Development Goals. Set goals require action. In contrast, in relation to the field of inner transformation, transformation might be understood as something that will happen if you focus on pursuing a certain practice or certain ethics/values - not on outcomes, e.g. reaching a certain goal. For example, the way Vipassana (a Buddhist meditation technique) is taught may be seen as a practice for change through reflexive processes and increasing self-reflective awareness. As a result, one might redefine relationships and attain fundamental change with oneself and the outer environment. In the face of endless 'urgencies' - how do we practice 'non-action', and should we? Participants' deliberated non-action as one of the paradoxes of sustainability:

"Meditation teaches us to reduce our reaction tendencies, act when really needed, and helps sharpen awareness that may bring about 'the art of inaction'... how can we widen those spaces of being and letting be... without making them." (Participant at Leverage Points session, see ESM S2)

Yet, as another participant remarked,

"The strong focus especially in our [western] culture on the doing and on the outer change obstructs the possibilities to have spaces for real change. Hence the question is how to balance better this 'doing mode' with the 'being mode'." (Participant at IST 2016 session, see ESM S1)

Inner change processes should thus not be equaled with non-action. In fact, they may be rather linked to the concept of emergence, as action and the need to act arises from specific circumstances without particular instrumental, forward or goal-oriented planning. This takes us to other ways of knowing. Participants emphasized the need to cultivate our sensitivity, develop intuition, which requires different ways of learning including being able to sense one's inner presence and being. 'Know thyself' then, would be one important imperative. Practices that explore complexities and multi-layeredness of our Inner Being support inner transformation. 
This view corresponds to recent studies, as put forward by Ghuman et al. (2019: 51-52):

"When we are integrated (acting with integrity), within ourselves and with the outside world, we are harmonious with the universe. We are parts of that harmonious whole, which expresses itself within and through us. The meaningful coincidences guide us and validate our thoughts and feelings about where we are and where we are going. And as a by-product, our behavior and decision-making very naturally becomes ethical and sustainable, which are not only of great value to our long-term success as an individual or as an organization but also critical for our survival on this planet."

This understanding is closely linked with studies on leverage points, where deep leverage points are identified as powerful areas for inducing potentially' transformational sustainability interventions' in the external world of processes and materials (Abson et al. 2016).

\section{The inner transformation- sustainability-nexus: towards deep leverage points for system change}

This section describes the inner transformation-sustainability nexus, i.e., the elements and mechanisms through which inner dimensions and sustainability are interrelated, and how they relate to leverage points of change. The section draws on the systematization of the sessions and the identified linkages to recent academic literature and reviews on inner transformation and sustainability (cf. Sect. "Approach and Methods"). In sum, results show that the inner transformation-sustainability nexus includes the following interrelated elements:

1. Subjective well-being and physical health

2. Self-reflection and awareness ${ }^{7}$

3. Activation of (intrinsic/non-materialistic) core values

4. Pro-environmental and pro-social attitudes (e.g., consumption choices and social activism)

5. Deliberate, flexible, and adaptive attitudes (e.g., to climate change, conflict resolution)

6. Sense of inter-connectedness, compassion, equity and social justice

\footnotetext{
7 Wamsler separates the elements of the nexus that are expressions of certain values, beliefs and worldviews from the emotional/ cognitive and relational capacities (also called transformative qualities or skills) that enable them, such as self-reflection and awareness, compassion, etc. Together they form part of the concept of mindsets (cf. Wamsler et al. 2018, Wamsler 2020, 2018a, b).
}

7. Human-nature connectedness

8. Sustainability-oriented social learning and innovation (including integration of different ways of knowing) (cf. nexus elements presented in Wamsler et al. 2018 and Wamsler 2018a, b)

All elements of the nexus relate to people's values, beliefs, worldviews and associated emotional/cognitive and relational capacities that, when activated can influence different sustainability outcomes and elements. Examples are the design of sustainability innovations, rules to structure system set up, or certain patterns of behavior (cf. Ives et al. 2019; Schäpke and Rauschmayer 2014; Wamsler et al. 2018). The identification of such elements allows for a differentiated understanding of areas and mechanisms through which inner transformation can support societal change towards sustainability (cf. Wamsler et al. 2018; Ives et al. 2019). They also show that the inner transformation-sustainability-nexus is manifold, relating to different scales, the individual, collective/social, and systems level (Wamsler 2018a; Wamsler et al. 2018). Deepening the understanding of this nexus may provide highly informative for attempts to govern sustainability transformations. In the following text we will provide some illustrative examples of the identified elements of the inner transformation-sustainability nexus and their interrelations.

Inner transformation strongly relates to individual and collective, subjective well-being and health, which is one key element of our quality of life (cf. Ives et al. 2019; Brown and Kasser 2005). In combination with a sense of justice, quality of life is a key aim of anthropo/eco-centric understandings of sustainability - and related policy making (cf. Rauschmayer et al. 2015).

Inner transformation is also closely related to inner capacities, such as self-reflection and awareness, which influences our worldviews (cf. Wamsler et al. 2020, O’Brien 2020). Concrete examples are the relatedness of humans and nature and mindfulness, which can for instance support conscious choices and behavior by minimizing automatic reactions or routines (cf. Wamsler et al. 2018; Brown and Kasser 2005).

Increased self-reflection and awareness can also relate to the activation of core values (such as pro-social, pro-environmental or transcendental values) and the narrowing of value-action gaps, leading to more sustainable individual and collective behavior (cf. Wamsler 2018b; Schäpke and Rauschmayer 2014; Horcea-Milcu et al. 2019; Brink and Wamsler 2019; Raymond and Kenter 2016).

Inner transformation thus does not merely relate to psychological, cognitive or emotional processes, but can translate into concrete behavior in various domains (e.g., consumption, social activism, conflict resolution) (cf. Wamsler et al. 2018, O'Brien 2018). It relates to a sense of interconnectedness to one's self, others and nature, and 


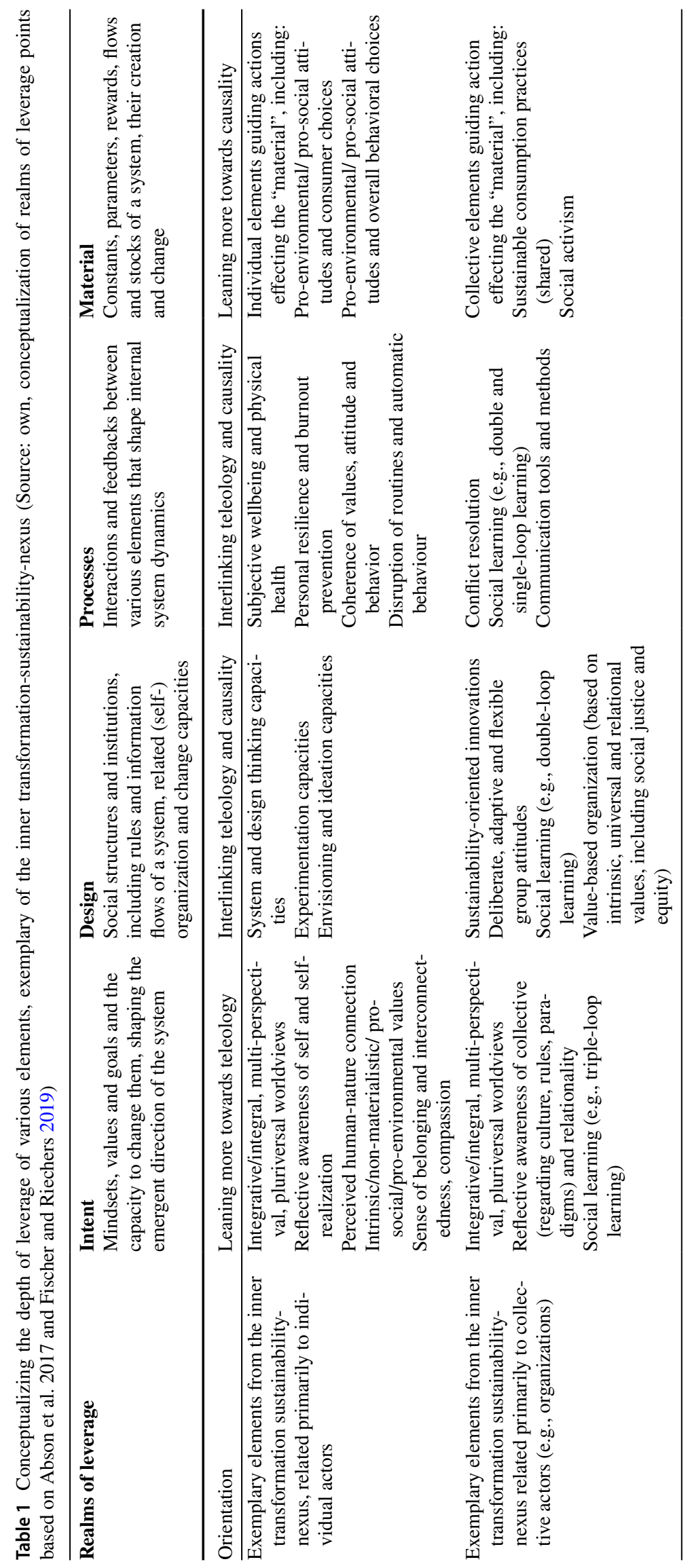


an orientation towards justice, as central principle of sustainability (Pfattheicher et al. 2016; Jacob et al. 2009). A variety of religious and spiritual worldviews and related practices, often of eastern or indigenous origin, do include and strengthen a sense of interconnectedness and compassion with the human and non-human world as well as an active engagement to change/work on oneself (cf. Dhiman and Marques 2016; Hedlund-de Witt et al. 2014; Ives and Kidwell 2019; Ives et al. 2018; Rauschmayer 2019).

The identified elements show that inner transformation can play an important role regarding sustainable behavior, including responses to complex and persistent problems, such as climate change (cf. Wamsler and Brink 2018; Wamsler 2018b; Ives et al. 2019, O’Brien 2018). It involves the facilitation of social learning and innovation as a key driver of transformation. Social learning leads to new understandings of the rules and structures underlying persistent problems and how to change these 'root causes' (e.g., double loop learning, cf. Reed et al. 2010; Armitage et al. 2008). Additionally, it relates to recognizing and improving the performance of existing structures (single-loop learning, cf. Fazey et al. 2018 based on Waddell 2016; Reed et al. 2010). Last, it includes to collectively understand and open up sense making and purpose development, thereby creating formerly unimagined possibilities to resolve problems (e.g., triple loop learning, cf. Fazey et al. 2018 based on Wadell 2016, cf. Johanessen et al. 2019). The integration of different ways of knowing (e.g., scientific, tacit and indigenous) can benefit the development of such new perspectives (cf. Fazey et al. 2020; Armitage et al. 2008; Raymond et al. 2010).

Sustainability oriented innovations include the ideation of new structures and rules, orienting the reorganization of systems towards sustainability (cf. Schot and Steinmueller 2018; Avelino et al. 2019). In this context, learning and innovation benefit from groups of actors holding deliberate, adaptive and flexible attitudes easing information exchange, reflection and ideation. On the individual level, these processes catalyze and benefit from competencies of ideation, experimentation and system and design thinking ${ }^{8}$ (cf. Wamsler et al. 2020).

Overall, the systematization of the dialogue sessions and associated literature show that many of the elements of the inner transformation-sustainability nexus belong to the realm of deep leverage points (such as mindsets, paradigms, beliefs, worldviews), either directly or indirectly. Related discussions emerged mainly during the third and the fourth dialogue sessions. There was broad agreement that exploring these elements further helps to identify and

\footnotetext{
${ }^{8}$ Here the discourse on inner transformation relates to that on sustainability competencies (e.g., Wiek et al. 2011) and transformative skills (e.g., Wamsler et al. 2020), which are not considered in depth due to space limitations.
}

adequately address root causes and key underlying factors of persistent unsustainabilities. These are crucial to develop targeted interventions that may lead to large overall system change (Abson et al. 2016). In this context, Abson et al. (2016) emphasize the 'nested hierarchy' of leverage points whereby "deeper system characteristics constrain the types of interventions possible at shallower realms of leverage". Fischer and Riechers (2019) clarify that while shallow leverage points thereby follow a causal, materialistic logic, deeper leverage points belong to the realm of teleology providing aim and direction (see Fig. 1). This logic can also be applied to differentiate the depth of leverage of different elements of the inner transformation-sustainability nexus.

On the basis of these results, we developed a tentative clustering of the elements forming the inner-transformation-sustainability nexus into the four basic realms of leverage (Table 1). This clustering and differentiation allows for a discussion of the interrelation of causality and teleology related to different elements. Furthermore, and corresponding to the elaboration on the nexus elements above, we differentiate in this context individual and collective scales.

As shown in Table 1 and Fig. 1, the elements of the innertransformation-sustainability nexus can be associated with all four realms of leverage, from the material to processes, design and intent, both on individual and collective scales. For instance, individual and collective self-awareness may include awareness of paradigms and is located at the 'deep' end of the leverage points spectrum: the intentional. This is true as well for core values and their activation. In the realm of systems design, primarily collective activities are found. This underpins the role of innovations as well as social learning and adaptive and deliberate approaches for system transformation via their capacity to change system design. Elements in the realm of feedbacks relate to the interplay between inner transformation and sustainability in form of for instance wellbeing, health and conflict resolution. Individual and collective behavior, in form of consumption choices or social activism based on pro-environmental or pro-social attitudes, can contribute to altering, e.g., the parameters of the respective (social-ecological or socio-technical) systems.

This differentiation reveals that inner dimensions and related transformation do not go equally deep (cf. Table 1). For instance, consumption-related attitudes are on a relatively shallower level than values ('what matters') or worldviews that frame our view of the world and encompass values and attitudes (Hedlund-de Witt et al. 2014).

However, the presented systematization is not aimed to make judgements about the interrelation of elements from the different realms; that is, between causality and teleology. Yet, it may guide investigations on these interrelations, for instance on how certain values and self-awareness relate to a deliberate approach to sustainability challenges, conflict resolution capacities and/or social activism. 
Furthermore, the differentiation might allow assessing planned interventions regarding the depth of the leverage point they approach and how they take interrelations between leverage points into account. Which policies could for instance foster self-awareness and activation of intrinsic/ pro-environmental values? Which approaches could facilitate that self-awareness and value-activation transmit into the design of systems change, feedback-loops and finally material parameters of the system in question? Part of such investigations needs to be a clarification of what the system in question is and which elements it includes. System elements and related interventions require differentiation as well.

\section{Addressing leverage points of inner transformations in practice}

This section illustrates the conceptual elaborations of the previous two sections in practice. It presents concrete practice examples of working with elements of the inner transformation-sustainability nexus that were brought up during the reflection and dialogue sessions. In this context, current challenges and benefits are highlighted.

As part of the so-called TRANSIT project, more than 100 related local initiatives and 20 global networks were studied (transitsocialinnovation.eu; Wittmayer et al. 2019). It showed that it is crucial to address inner dynamics to both respond to challenges whilst supporting a thriving society and planet. About a third of the analyzed initiatives under study had experienced internal crises, for instance around leadership, power, finances, aims or values. TRANSIT showed that social learning, including processes of selfreflection, emotional learning and inner transformation more broadly were of high value to deal with such crises in support of sustainability (Kunze and Avelino 2015; Dumitru et al. 2016). Many of the analyzed social innovation initiatives have developed specific approaches to work with inner transformation on the individual and collective level. The two examples ${ }^{9}$ presented below are ecovillages that form part of the Global Ecovillage Network and the Transition Movement.

\footnotetext{
9 The illustrative examples are chosen on the basis of the expertise, experience and research conducted by co-authors of this paper. We are aware of the limitations of the examples with regards to their scale and specific context, and do not claim comprehensiveness nor broad representativeness. Further relevant initiatives exist, e.g., platforms created for policy makers and other change agents to allow them developing their cognitive/emotional and relational capacities, to increase democratic governance and sustainability.
}

\section{The Global ecovillage network}

Ecovillages are living examples of self-organized social systems that have experience with linking inner and outer change for sustainability at a local level (e.g., Kunze 2012; Kunze and Avelino 2015; Veciana et al. 2020). There are diverse key drivers for ecovillagers self-organizing in projects to create a sustainability culture in their own and neighboring villages (cf. Veciana and Strünke 2018). Among the motivations mentioned by the interviewed villagers is the wish to support a culture of consciousness and self-reflection, e.g., by discussing common values and associated actions. Additional motivators are a sense of belonging and togetherness, and the longing to solve conflicts together, for instance by using effective communication methods.

Many ecovillagers believe that sustainability involves addressing individual mindsets and the support of personal development for agency towards more responsible, cooperative behavior. As a villager living in Findhorn states:

"We do a lot of sharing: Being heard, sitting in a circle; the sharings can go very deep... Some people and guests say it is the first time they feel really heard... an atmosphere, very open hearted... it is mind-blowing and heart-blowing... a lot of people go away completely transformed." (Interview GEN2 in Kunze and Avelino 2015).

A recent study found that people tend to feel frustrated or overwhelmed by theoretical information and approaches towards sustainability, e.g., about Sustainable Development Goals (Veciana et al. 2020); In contrast, they feel inspired by visiting ecovillages. The direct experience and mutual exchange about inner and outer aspects of sustainability is crucial not only to gain real-world examples and information, but also to develop inner motivation and orientation.

This inspirational power of ecovillages raises the question of how ecovillagers' perspectives, values, beliefs, emotional and habitual patterns, and bodily experiences relate to their daily practice in shaping sustainable lifestyles. In their daily lives, ecovillagers continually challenge existing paradigms by experimenting and testing new patterns for a sustainable lifestyle through both, inner and outer practices and approaches (Fig. 2).

There are thus diverse practices and approaches to address elements of the inner-transformation-sustainability nexus to learn from. Many of these can be related to deep leverage points, fostering being open 'to not knowing' and to continuously question own worldviews with a self-reflexive attitude. The aim of the different practices and approaches is to address elements of the inner-transformation-sustainability nexus at an intra-personal, inter-personal and community level (Veciana and Ottmar 2018). At all these levels inner barriers towards change may emerge during the 


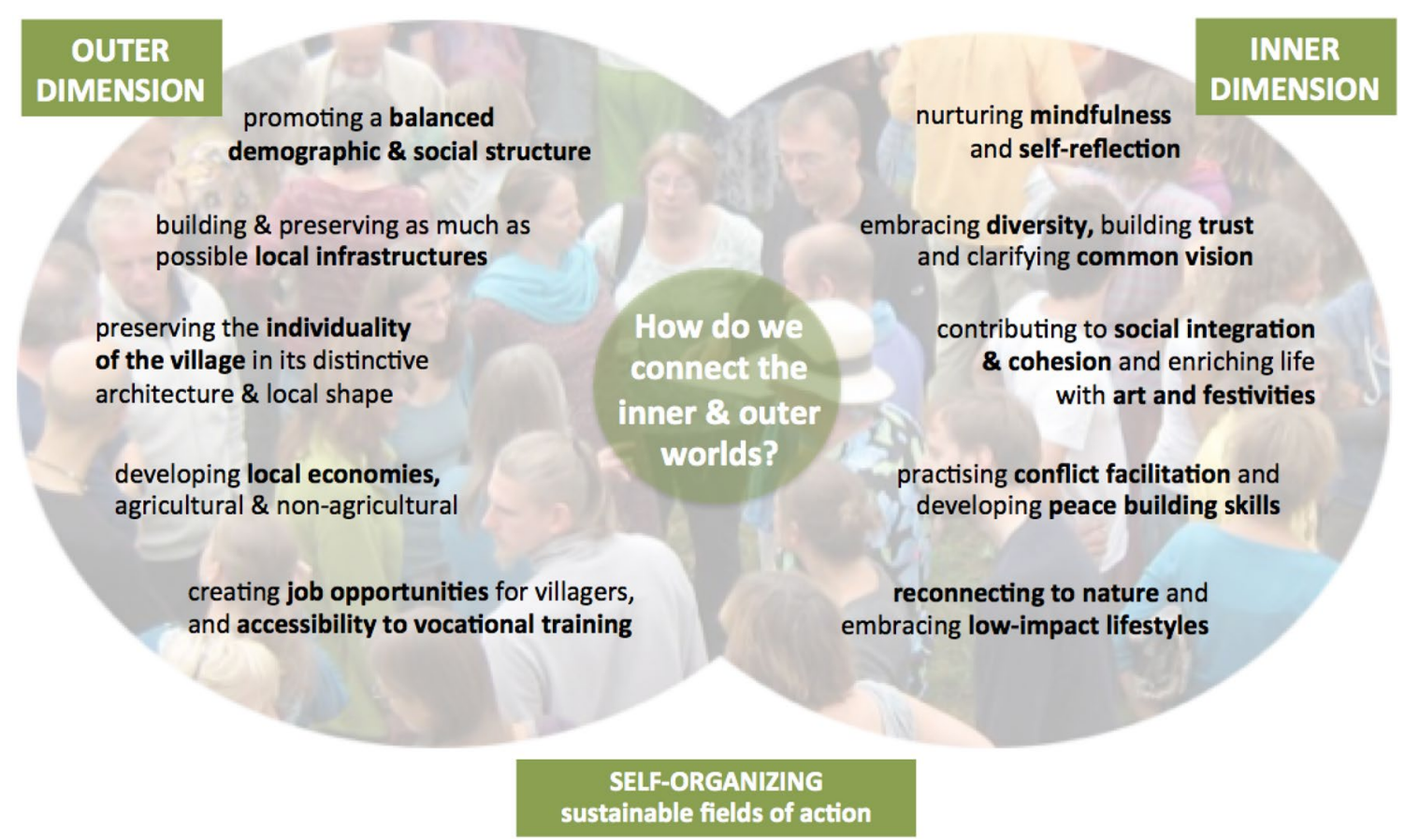

Fig. 2 Connecting inner and outer sustainable fields of self-organized action-the case of ecovillages, (S. Veciana for the conference Leverage Points 2019, Lüneburg)

process of developing a new sustainable lifestyle. To overcome inner barriers and foster agency, ecovillagers actively learn through different individual and collective methods to express themselves in group processes regarding any social, ecological, economical or cultural matter (Veciana and Ottmar 2018). The resultant creative engagement of self-empowered individuals reportedly shapes the group processes, together with a willingness to focus on achieving the 'best solution for the whole'.

\section{The transition movement}

The Transition Movement is another initiative which recognizes and develops what members call 'inner transition' (Longhurst 2015; Prentice 2012). Even though there are now more than 1000 such transition initiatives worldwide, it is still a young movement that originated in 2006. One of the inner transition trainers noted the following during a session:

"There are many great people, but what we haven't actually learned in our society is working together. Finding a way for creating a learning community is a salient dimension in the inner transition approach. We are trying to work with existing hierarchies to bring the inner understanding out in communication, for example in a 'circle culture'. When people come together, and they are open, something new can be created, which is more than the sum of the pieces."

(Gräf, expert at IST 2016, ESM S1).

This notion of inner transition ideally permeates all activities of the Transition Movement:

"Everything we do, e.g., building up new structures in economies, in every area inner transition is always present. The head, the heart and the hands are all together".

(Gräf, IST 2016, ESM S1).

Similar to the Global Ecovillage Network, this approach also intends to empower people through self-reflection, self-organization and facilitating personal development to tap into everyone's full potential. The aim is that people start acting, not only as individuals but also jointly, by taking responsibility and work together in interconnected ways:

"The individual and the collective position are both variable and have to be connected with something we call 'inner source"” (Gräf, IST 2016, ESM S1).

The work of the Transition Movement suggests that the 'heart dimension' or this 'inner source' can naturally emerge when people work together in projects. Here, people face conflicts, crises and emotional challenges, which often require them to redefine their perspectives and personal 
relationships (Power 2016). This is also one of the reasons why the so-called 'Heart and Soul Groups' were initiated early on as part of the Transition Movement to explore the psychology of change (Hopkins 2011). As observed by Gräf (IST 2016, ESM S1):

"[...] no matter how you start, it [the inner dimension] always comes in. It is important when people are encountering the diversity of life in projects. In the local workshops and trainings, people themselves always come up with it [the role of inner dimensions]."

Consequently, various methods and levels to address inner dimension and transformation are used (see ESM 3).

A key issue and challenge for addressing the inner transformation-sustainability nexus in practice is the diversity of potential approaches and practices, many of which are rooted in ethical/psychological, spiritual or religious traditions. Experience of participating transition trainers has shown that what brings people together is that they engage together in certain practices that do not have a connotation of only one particular tradition or school. Those that are more universal and uniting are more accessible to everybody.

Finally, it has to be noted that there are many other emerging initiatives that aim at developing inner capacities or qualities to foster change towards sustainability at collective and systems level, including the development of new methods, tools and technologies. At the same time, research regarding the effectiveness of different approaches to support transformational skills and sustainability outcomes at different scales is still in its infancy (Wamsler 2020; Ives et al. 2019).

\section{Discussion and conclusions}

\section{Inner transformation-sustainability nexus and the leverage points perspective}

Our study shows that inner dimensions and transformation are essential to understand and facilitate personal and collective processes of change in terms of our awareness and relationship to ourselves, others, and the environment. In addition, we identify the key elements of the inner-transformation-sustainability nexus, which are today discussed in disperse studies and fields that deal with inner transformation and/or sustainability more broadly. The identification of these elements allows for a differentiated understanding of areas and mechanisms through which inner dimensions and transformation can play a role in societal change towards sustainability. This includes, amongst other things, processes related to self-reflection and awareness at individual and collective level, and the activation of core values, universal principles (such as equity and social justice) and associated behavior, a sense of human-nature connectedness, as well as sustainability-oriented social learning and innovation towards sustainability.

Furthermore, this paper links the inner transformation-sustainability nexus to the leverage points concept. This offers a powerful perspective to understand and potentially facilitate societal transformation. Inner dimensions as leverage points for transformation put emphasis on the role of the individual, while not ignoring the necessity for collective and systems change (Schäpke 2018; Wamsler 2020). Ethical arguments suggest that the most legitimate ways to address inner dimensions and transformation may come through transformative education and voluntary changes by individuals or groups interested in expanding their agency (O'Brien and Sygna 2013; Rauschmayer et al. 2015; Wamsler et al. 2020). Potential approaches include the development of spaces and methods that can support selfawareness and -reflection, perspective-seeking, values-based engagement and care for oneself, others and the environment (Sect. "Addressing leverage points of inner transformations in practice"; cf. Wamsler et al. 2020; Pereira et al. 2020). An expansion of individual agency, awareness and broadening of perspectives, is likely to facilitate the emergence of a new paradigm or worldview, which is considering wider circles of care and impact from individual human action to a broader consideration of human and non-human life (see Sect. "The inner transformation-sustainability-nexus: Towards deep leverage points for system change", cf. O'Brien 2020, Hedlund-De Witt 2012). According to the leverage points framework (Fig. 1), interventions targeting such deep leverage points can (potentially) create a strong impulse for overall systems change.

Interventions also include the acknowledgement of inner dimensions for social change towards sustainability by developing more comprehensive approaches in various fields, for instance in urban development (Woiwode 2012 and 2016). This is key for complementing current technology and information-focused approaches by systematically considering and integrating/mainstreaming inner dimensions in project design, implementation and communication. The leverage points perspective is a useful lens to locate elements of the inner transformation-sustainability nexus along the spectrum of teleology and causality or, in other words, deep and shallow leverage points (ESM 3). We developed such a tentative positioning of the different elements to help guide the analysis of approaches aimed at addressing inner dimensions and transformation for sustainability, e.g. regarding policies.

Further analyses are needed to look into the interplay between different elements related to teleology (intents) and causality (parameters and feedbacks) and to elaborate on the role of certain elements for larger system change. As a 
consequence of such enhanced frameworks and understanding, it would be easier to assess and anticipate the implications and impact of specific interventions as discussed in Sect. "The inner transformation-sustainability-nexus: Towards deep leverage points for system change". Yet, it is challenging to establish empirical connections between people's inner dimensions and transformation, and the impact on actual behavior, because such dimensions are ideational cultural expressions. Research on how to support inner qualities or skills for transformation is thus crucial and increasingly emerging, for instance in the context of activating climate negotiations and actions (Wamsler et al. 2020).

\section{Practices and challenges of current inner transformation approaches}

The presented illustrative examples point towards the diverse approaches and practices that are currently used to support individual and collective processes of transformational change. They highlight the boundedness of such practices in specific spatial and social contexts.

Approaches and practices which address inner dimensions and transformation influence changes that relate to all levels of the spectrum between the teleological and the causal (e.g., in the 'Collaboratory' when visions are transferred into designs of prototypes and decisions on actions, Muff 2014). While the influence can be associated more with individual or collective levels, approaches and practices relate to both levels.

Furthermore, from the various discussions in the conference sessions on current practices, a number of challenges emerged. One repeatedly mentioned challenge is the time factor in terms of both overall time scale and pace. Whilst there is a feeling of urgency to enact (inner and outer) transformation, e.g., for responding to climate change, it requires time to develop personal integrity, reflection and openness to oneself, others and nature. Yet, at first sight this seems to collide with the fast pace of life which leaves no or insufficient time for regular personal inner practice. This is also increasingly mentioned as an issue within the research environment, forcing academics to rush from one project and grant to the next, restricting the possibility to reflect and engage with ideas in a 'Goethean' way over longer periods of time. At the same time, this situation further supports the importance of simultaneously addressing inner and outer aspects of sustainability for more 'effective' action.

As demonstrated by the practice examples, creating 'safe spaces' for reflection and joint action is needed to enable individual and collective change. It is crucial to support individuals and groups in a process of connecting to the 'whole', including issues of personal values, beliefs, worldviews, religion, spirituality, or to talk about emotions, including joy and happiness or fear and anger. Talking about these aspects is not common ground in sustainability research, practice and education (Ives et al. 2019; Hendersson and Wamsler 2020). However, they are part of people's everyday lives and influence sustainability at all levels. Addressing such issues requires a protective environment, where differences are more likely to be accepted, conflicts can be addressed, and the main goal is to connect for the common good. Relatedly, we argue for practices that support relationality in the context of inner dimensions and transformation (Walsh et al. 2020).

\section{Inner transformation in research and academia}

Based on the authors' experience of convening the conference sessions, forming a network of a community of practice, and their academic enquiries, it is clear that there is an increasing number of scholars that engage in transformative research, inner dimensions and transformation towards sustainability. Often, these scholars are engaged in both research and practice, with a distinct biographical narrative interweaving these two realms. Consequently, many of them actively go beyond a rigorous subject-object distinction as typical for positivist science (see Fazey et al. 2018). We can observe an increasing openness regarding the issue of inner transformation (e.g., conferences that host related sessions, special issues of academic journals on the issue). Yet, the traditional approaches and structures of research institutes and universities-at least in Europe-still hamper the integration of transformative learning and inner transformation in sustainability-related education programs (Wamsler 2020). This skepticism is, amongst other things, rooted in how the academic world defines and conceptualizes knowledge (Fazey et al. 2020). In fact, the field of inner transformation challenges traditional approaches and structures by arguing for the inclusion of different modes of knowledge in a transdisciplinary way (Woiwode 2020 forthcoming). At the same time, the emergence of the environmental humanities as well as innovative courses and approaches that integrate inner and outer sustainability (cf. Wamsler 2020) is pointing in the right direction.

The present study does not allow deriving generic recommendations for how to address inner dimensions and transformation in research practice, due to both the limited scope of the study and the high context dependency of inner transformation practices. However, approaches to research that encompass co-creative and reflexive forms of knowledge creation (such as transdisciplinary, action-oriented and transformative research; Lang et al. 2012; Fazey et al. 2018) appear generally suitable for both the analysis and the (potential) engagement with inner dimensions. These forms of knowledge creation often go hand in hand with changed roles researchers take, with (self-)reflection and dialogue 
being core activities (Wittmayer and Schäpke 2014). Such innovative approaches combine knowledge co-creation tools with specific facilitation methods acknowledging the importance of inner dimensions of participants and researchers alike (e.g., 'art of hosting' [Quick and Sandfort 2014], 'co-creative relfection and dialogue space' [Wamsler et al. 2020]).

\section{Areas for further research on inner transformation}

Finally, our results and the discussions during the conference sessions and amongst the inner transformations group members brought forward several research areas, which need to be developed further to critically explore the role of inner transformation for sustainability:

1. Conceptual and theoretical understanding of inner transformation and how its various elements relate to different theories and practices of change, including sustainability transitions and transformations research (theoretical point of view);

2. Linkages between the identified dimensions of inner transformation and transdisciplinarity, action-oriented, transformative or other methods and approaches to support sustainability;

3. Place based empirical studies to learn from the diversity of existing approaches and possibilities of inner transformation for collective and systems change;

4. Domain- and culture-specific empirical studies to learn from the diversity of aspects and contents of transformation to honour the myriad of relevant dimensions of 'inner' that can and should be studied at both individual and cultural/collective levels;

5. Cross-cultural studies to understand the 'bigger picture' in terms of impact, commonalities and differences (e.g., socio-political, historical, philosophical-ethical, religious circumstances);

6. Identification of the inner capacities, qualities or skills that can foster certain elements of the inner transformation-sustainability nexus and the methods and tools that can best support them;

7. The role of governance (variety of players, stakeholders at different levels and in different domains) regarding the development and impact of certain methods, approaches and tools;

8. Relationship to policy and project planning in an intentional, purposeful approach of mainstreaming or integrating inner transformation into sustainability and across all sectors, and how to address related barriers, constraints and conflicts that may arise (future pathways).
Acknowledgements We are grateful to the participants, discussants, scholars, experts and practitioners who participated in the conference sessions and the invited panellists Anaim Gräf, Dr. Martin Held, Susanne Lutz, Tobias Meier and Dr. Markus Molz. Funding for travel of invited panelists was received from Deutsches Institut für Entwicklungspolitik (DIE) for the IST 2016 Conference session. Niko Schäpke acknowledges funding from the Swedish Foundation for Strategic Environmental Research (MISTRA), as part of a MISTRA fellowship. Finally, Christine Wamsler acknowledges funding from the Swedish Research Council Formas for the projects Mind4Change (Grant number 2019-00390; full title: Agents of Change: Mind, Cognitive Bias and Decision-Making in a Context of Social and Climate Change) and TransVision (Grant number 2019-01969; full title: Transition Visions: Coupling Society, Well-being and Energy Systems for Transitioning to a Fossil-free Society).

Funding Open Access funding enabled and organized by Projekt DEAL.

Open Access This article is licensed under a Creative Commons Attribution 4.0 International License, which permits use, sharing, adaptation, distribution and reproduction in any medium or format, as long as you give appropriate credit to the original author(s) and the source, provide a link to the Creative Commons licence, and indicate if changes were made. The images or other third party material in this article are included in the article's Creative Commons licence, unless indicated otherwise in a credit line to the material. If material is not included in the article's Creative Commons licence and your intended use is not permitted by statutory regulation or exceeds the permitted use, you will need to obtain permission directly from the copyright holder. To view a copy of this licence, visit http://creativecommons.org/licenses/by/4.0/.

\section{References}

Abson DJ, Fischer J, Leventon J, Newig J, Schomerus T, Vilsmaier $\mathrm{U}$, von Wehrden $\mathrm{H}$, Abernethy P, Ives CD, Jager NW, Lang DJ (2016) Leverage points for sustainability transformation. Ambio 46:30-39. https://doi.org/10.1007/s13280-016-0800-y

Adger WN, Barnett J, Brown K, Marshall N, O'Brien K (2013) Cultural dimensions of climate change impacts and adaptation. Nat Climate Change 3(2):112-117

Armitage D, Marschke M, Plummer R (2008) Adaptive co-management and the paradox of learning. Global Environ Change 18(1):86-98

Avelino F, Wittmayer JM, Pel B, Weaver P, Dumitru A, Haxeltine A et al (2019) Transformative social innovation and (dis) empowerment. Technol Forecast Soc Chang 145:195-206

Bendell J (2018) Deep adaptation: a map for navigating climate tragedy. Institute for Leadership and Sustainability (IFLAS) Occasional Papers Volume 2. University of Cumbria, Ambleside, UK. (Unpublished) http://insight.cumbria.ac.uk/id/eprint/4166/

Berger P, Hock K, Klie T (eds) (2013) Religionshybride. Religion in posttraditionalen Kontexten. Springer VS Verlag, Wiesbaden, pp. $187-200$

Bhaskar R (2002a) From science to emancipation: alienation and the actuality of enlightenment. Sage, London

Bhaskar R (2002b) The philosophy of metareality: creativity, love and freedom. Routledge, London

Blythe J, Silver J, Evans L, Armitage D, Bennett NJ, Moore ML et al (2018) The dark side of transformation: latent risks in contemporary sustainability discourse. Antipode 50(5):1206-1223 
Brink E, Wamsler C (2019) Citizen engagement in climate adaptation surveyed: the role of values, worldviews, gender and place. Cleaner Prod 209:1342-1353

Brown KW, Kasser T (2005) Are psychological and ecological wellbeing compatible? The role of values, mindfulness, and lifestyle. Soc Indic Res 74(2):349-368

Bucher AA (2007) Psychologie der Spiritualität. Psychologie Verlagsunion, Weinheim

Combs A (1996) The radiance of being. Paragon House, St. Paul, Minn

D'Alisa G, Demaria F, Kallis G (eds) (2014) Degrowth: A Vocabulary for a New Era. Routledge, New York \& London

Dev A (2018) Into great depth of your being. A guided exploration into eight parts of your inner being. AuroPublications, Pondicherry

Dhiman S, Marques J (eds) (2016) Spirituality and sustainability: new horizons and exemplary approaches. Springer International, Switzerland

Dumitru A, Lema-Blanco I, Mira R-C, Kunze I, Strasser T, Kemp $\mathrm{R}$ (2016) Social learning for transformative social innovation. TRANSIT deliverable 2.3. TRANSIT:EU SSH.2003.3.2-1 Grant Agreement n.613169

EEA (2016) Sustainability transitions: now for the long term. Copenhagen: European Environment Agency (EEA), European Environment Information and Observation Network (EIONET)

Fazey I, Schäpke N, Caniglia G, Patterson J, Hultman J, Van Mierlo B et al (2018) Ten essentials for action-oriented and second order energy transitions, transformations and climate change research. Energy Res Social Sci 40:54-70. https://doi. org/10.1016/j.erss.2017.11.026

Fazey I, Schäpke N, Caniglia G, Hodgson A, Kendrick I, Lyon C, Page G, Patterson J, Riedy C, Strasser T, Verveen S et al (2020) Transforming knowledge systems for life on Earth: Visions of future systems and how to get there.Energy Res Social Sci. https://doi.org/10.1016/j.erss.2020.101724

Feuerstein G, Feuerstein B (2007) Green Yoga. Traditional Yoga Studies, Eastend

Fischer J, Riechers M (2019) A leverage points perspective on sustainability. People Nat 00:1-6. https://doi.org/10.1002/pan3.13

Gardner G (2002) Invoking the Spirit: Religion and Spirituality in the Quest for a Sustainable World. Worldwatch Paper 164. Worldwatch Institute

Geels FW, Schot J (2007) Typology of sociotechnical transition pathways. Res Policy 36:399-417

Ghuman K, Wride MA, Franses P (2019) Practical spirituality: the art and science of conscious living. In: Giri AK (ed) Practical spirituality and human development: creative experiments for alternative futures. Palgrave Mcmillan, Singapore, pp 39-57

Giri AK (2018) The calling of practical spirituality. In: Giri AK (ed) Practical spirituality and human development: transformations in religions and societies. Palgrave Mcmillan, Singapore, pp 13-29

Göpel M (2016) The Great Mindshift: how a new economic paradigm and sustainability transformations go hand in hand. SpringerOpen

Habermas J (2001) Glauben und Wissen. Friedenspreis des Deutschen Buchhandels 2001. Suhrkamp, Frankfurt am Main

Hedlund-de Witt A (2012) Exploring worldviews and their relationships to sustainable lifestyles: Towards a new conceptual and methodological approach. Ecological Economics 8474-83

Hedlund-de Witt A, De Boer J, Boersema JJ (2014) Exploring inner and outer worlds: a quantitative study of worldviews, environmental attitudes, and sustainable lifestyles. J Environ Psychol 37:40-54

Heelas P, Woodhead L (2005) The spiritual revolution: why religion is giving way to spirituality. Blackwell, Oxford
Hendersson H, Wamsler C (2020) New stories for a more conscious, sustainable society: claiming authorship of the climate story. Climatic Change 158:345-359

Hochachka G (2005) Developing Sustainability, Developing the Self: An Integral Approach to International and Community Development. BC, Canada: Drishti Centre for Integral Action. www.drish ti.ca (Retrieved 04/05/2009)

Hopkins R (2011) The transition companion: making your community more resilient in uncertain times. Green Books, Totnes

Horcea-Milcu A-I, Abson DJ, Apetrei CI, Duse IA, Freeth R, Riechers M (2019) Values in transformational sustainability science: four perspectives for change. Sustain Sci. https://doi.org/10.1007/ s11625-019-00656-1

Horlings LG (2015) The inner dimension of sustainability: personal and cultural values. Curr Opinion Environ Sustain 14:163-169. https://doi.org/10.1016/j.cosust.2015.06.006

Hulme M (2009) Why we disagree about climate change: understanding controversy, inaction and opportunity. Cambridge University Press, Cambridge

Hunecke M (2018) Psychology of sustainability: psychological resources for sustainable lifestyles. In: Parodi O, Tamm K (eds) Personal Sustainability. Exploring the Far Side of Sustainable Development, Routledge, pp 33-50

Ives CD, Kidwell J (2019) Religion and social values for sustainability. Sustain Sci. https://doi.org/10.1007/s11625-019-00657-0

Ives C, Abson D, von Wehrden H, Dorninger C, Klaniecki K, Fischer J (2018) Reconnecting with nature for sustainability. Sustain Sci 13:1389-1397

Ives CD, Freeth R, Fischer J (2019) Inside-out sustainability: the neglect of inner worlds. Ambio. https://doi.org/10.1007/s1328 0-019-01187-w

Jackson T (2009) Prosperity without Growth. Earthscan, London

Jacob J, Jovic E, Brinkerhoff MB (2009) Personal and planetary wellbeing: Mindfulness meditation, pro-environmental behavior and personal quality of life in a survey from the social justice and ecological sustainability movement. Soc Indic Res 93(2):275-294

Johannessen $\AA$, Gerger Swartling $\AA$, Wamsler C, Andersson K, Arran JT, Hernández Vivas DI, Stenström TA (2019) Transforming urban water governance through social (triple-loop) learning. Environ Policy Governance 29(2):144-154

Knoblauch H (2009) Populäre Religion: Auf dem Weg in eine spirituelle Gesellschaft. Campus, Frankfurt am Main

Köhler J et al (2019) An agenda for sustainability transitions research: state of the art and future directions. Environ Innovation Soc Transitions. https://doi.org/10.1016/j.eist.2019.01.004

Kothari A, Salleh A, Escobar A, Demaria F, Acosta A (eds) (2019) Pluriverse. A post-development dictionary. Tulika Books, New Delhi

Kunze I (2012) Social innovations for communal and ecological living. Lessons from sustainability research and observations in intentional communities. Communal Soc 32(1):50-67

Kunze I, Avelino F (2015) Social innovation and the Global Ecovillage Network (TRANSIT research report), TRANSIT: EU SSH.2013.32-1 Grant agreement no: 613169 http://www.trans itsocialinnovation.eu/resourcehub/global-ecovillage-network-gen

Lang DJ, Wiek A, Bergmann M, Stauffacher M, Martens P, Moll P et al (2012) Transdisciplinary research in sustainability science: practice, principles, and challenges. Sustain Sci 7(1):25-43

Leach M, Raworth K, Rockström J (2013) Between Social and Planetary Boundaries: Navigating pathways in the safe and just space for humanity. ISSC and UNESCO (Eds.) World Social Science Report 2013: Changing Global Environments. OECD Publishing and UNESCO Publishing, Paris, pp 84-89

Leal Filho W, Consorte McCrea A (eds) (2019) Sustainability and the Humanities. Springer Nature, Cham 
Lockhart H (2011) Spirituality and Nature in the Transformation to a More Sustainable World: Perspectives of South African Change Agents. Dissertation at the Stellenbosch University: South Africa

Longhurst N (2015) Towards an 'alternative' geography of innovation: alternative milieu, socio-cognitive protection and sustainability experimentation. Environ Innovation Soc Transitions 17:183198. https://doi.org/10.1016/j.eist.2014.12.001

Manfredo MJ, Bruskotter JT, Teel TL, Fulton DC, Oishi S, Uskul AK et al (2017) Revisiting the challenge of intentional value shift: reply to Ives and Fischer. Conserv Biol 31(6):1486-1487

Martínez-Alier J, Pascual U, Vivien FD, Zaccai E (2010) Sustainable de-growth: Mapping the context, criticisms and future prospects of an emergent paradigm. Ecol Econ 69(9):1741-1747

Meadows DH (1999) Leverage points: places to intervene in a system. The Sustainability Institute, Hartland

Meadows DH (2008) Thinking in systems: a primer. Chelsea Green Publishing, London

Muff K (ed) (2014) The Collaboratory. Greenleaf Publishing Book

O'Brien K (2018) Is the $1.5 \mathrm{C}$ target possible? Exploring the three spheres of transformation. Current Opinion Environ Sustain $31: 153-160$

O'Brien K (2020) You Matter More Than You Think: Quantum Social Change in Response to a World in Crisis. Unpublished manuscript circulated for feedback in June 2020, AdaptationCONNECTS, University of Oslo, Norway

O'Brien K, Sygna L (2013) Responding to Climate Change: The Three Spheres of Transformation. Proceedings of the Conference Transformation in a Changing Climate, ed. University of Oslo, pp. 16-23

O'Riordan T, Lenton T (eds) (2013) Addressing tipping points for a precarious future. Oxford University Press, Oxford

Ott HE, Sachs W (2016) Letzte Zuflucht Glauben: Der Beitrag der Spiritualität zur Erhaltung einer lebenswerten Welt. In Religion und Spiritualität: Ressourcen für die Grosse Transformation? [Religion and Spirituality: Resources for a Great Transformation?]. Politische Ökologie 147:17-24

Parodi O, Tamm K (2018) Personal sustainability: exploring the far side of sustainable development. Routledge, London

Pereira L, Frantzeskaki N, Hebinck A, Charli-Joseph L, Drimie S, Dyer $M$ et al (2020) Transformative spaces in the making: key lessons from nine cases in the Global South. Sustain Sci 15(1):161-178

Pfattheicher S, Sassenrath C, Schindler S (2016) Feelings for the suffering of others and the environment: compassion fosters proenvironmental tendencies. Environ Behav 48(7):929-945

Power C (2016) The integrity of process: is inner transition sufficient? J Social Political Psychol 4(1):347-363. https://doi.org/10.5964/ jspp.v4i1.538

Prentice H (2012) "Heart and soul": Inner and outer in the Transition Movement. In: Rust M-J, Totten N (eds) Vital signs: psychological responses to ecological crisis. Karnac, London

Quick K, Sandfort J (2014) Learning to facilitate deliberation: practicing the art of hosting. Critical Policy Studies 8(3):300-322

Rauschmayer F (2019) The transition to sustainability as interbeing... or: from oncology to ontology. In: Meadowcroft J, Banister D, Holden E, Langhelle O, Linnerud K, Gilpin G (eds) What next for sustainable development? Edward Elgar Publishing, Cheltenham, pp 181-199

Rauschmayer F, Bauler T, Schäpke N (2015) Towards a thick understanding of sustainability transitions-linking transition management, capabilities and social practices. Ecol Econ 109:211-221

Raworth K (2017) Doughnut economics: seven ways to think like a 21st century economist. RH Business Books, London

Raymond CM, Kenter JO (2016) Transcendental values and the valuation and management of ecosystem services. Ecosyst Services $21: 241-257$
Raymond CM, Fazey I, Reed MS, Stringer LC, Robinson GM, Evely AC (2010) Integrating local and scientific knowledge for environmental management. J Environ Manage 91(8):1766-1777

Reed MS, Evely AC, Cundill G, Fazey I, Glass J, Laing A, et al (2010) What is social learning?. Ecol Soc 15(4)

Rigby K (2017) Deep sustainability: ecopoetics, enjoyment and ecstatic hospitality. In: Squire L, Parham J, Johns-Putra A (eds) Literature and sustainability: exploratory essays. Manchester UP, Manchester, pp 52-75

Rockström J et al (2009) A safe operating space for humanity. Nature 461:472-475

Schäpke N (2018) Linking transitions to sustainability: individual agency, normativity and transdisciplinary collaborations in transition management. PhD Thesis. Leuphana University of Lüneburg. https://www.econstor.eu/handle/10419/182202

Schäpke N, Rauschmayer F (2014) Going beyond efficiency: including altruistic motives in behavioral models for sustainability transitions to address sufficiency. Sustain Sci Practice Policy $10(1): 29-44$

Scharmer CO (2009) Theory U: leading from the Future as it Emerges. Berret- Koehler, San Francisco

Scharmer CO, Kaufer K (2015) Awareness-based action research: catching social reality creation in flight. In: Bradbury $\mathrm{H}(\mathrm{ed}) \mathrm{The}$ SAGE handbook of action research. Sage Publications, London, pp 199-210

Schot J, Steinmueller WE (2018) Three frames for innovation policy: $\mathrm{R} \& \mathrm{D}$, systems of innovation and transformative change. Res Policy 47(9): 1554-1567

Seyfang G, Smith A (2007) Grassroots innovations for sustainable development: towards a new research and policy agenda. Environ Politics 16(4):584-603

Slaughter RA (2012) Welcome to the Anthropocene. Futures 44:119126. https://doi.org/10.1016/j.futures.2011.09.004

Ulluwishewa R (2014) Spirituality and sustainable development. Palgrave Mcmillan, Basingstoke

Upham P, Bögel P, Johansen K (2019) Energy transitions and social psychology: a sociotechnical perspective. Routledge, London

Veciana S, Ottmar K (2018a) Inner conflict resolution and self-empowerment as contribution for personal sustainability on the case of intentional community practices. In: Parodi O, Tamm K (eds) Personal sustainability: exploring the far side of sustainable development. Routledge, London, pp 116-135

Veciana S, Strünke C (2018b) Leben in zukunftsfähigen Dörfern. Ein Modellprojekt zur Unterstützung nachhaltiger ländlicher Entwicklung. In: Agrarsoziale Gesellschaft e.V. ASG (ed) Neue Ansätze für die Dorf- und Regionalentwicklung. Göttingen 03/2018, pp 26-29

Veciana S, Urbain H, Schwab A (2020) Leben in zukunftsfähigen Dörfern. Ökodörfer als Katalysatoren nachhaltiger Entwicklung. Projektstudie. Texte 21/2020, Eds.: Umweltbundesamt, Dessau-Roßlau

Waddell S (2016) Change for the audacious: a Doer's guide to large systems change for flourishing futures. Networking Action Publishing, Boston

Walsh Z, Böhme J, Wamsler C (2020) Towards a relational paradigm in sustainability research, practice and education. Ambio. https ://doi.org/10.1007/s13280-020-01322-y

Wamsler C (2018a) Contemplative sustainable futures: the role of individual inner dimensions and transformation in sustainability research and education. In: Leal Filho W, Consorte-McCrea A (eds) Handbook of sustainability and humanities. Springer, Cham, pp 359-374

Wamsler C (2018b) Mind the gap: the role of mindfulness in adapting to increasing risk and climate change. Sustain Sci 13:1121-1135. https://doi.org/10.1007/s11625-017-0524-3 
Wamsler C (2020) Education for Sustainability: fostering a more conscious society and transformation to sustainability. Int J Sustain Higher Edu 21(1): 112-130. https://www.emerald.com/insight/ content/doi/10.1108/IJSHE-04-2019-0152/full/html

Wamsler C, Brink E (2018) Mindsets for sustainability: exploring the link between mindfulness and sustainable climate adaptation. Ecol Econ 151:55-61

Wamsler C, Brossmann J, Hendersson H, Kristjansdottir R, McDonald C, Scarampi P (2018) Mindfulness in sustainability science, practice, and teaching. Sustain Sci 13(1):143-162. https://doi. org/10.1007/s11625-017-0428-2

Wamsler C, Schäpke N, Fraude C, Stasiak D, Bruhn T, Lawrence M, Schroeder H, Mundaca L (2020) Enabling new mindsets and transformative skills for negotiating and activating climate action: Lessons from the UNFCCC Conferences of the Parties. Environmental Science and Policy

WBGU (German Advisory Council on Global Change) (2011) World in Transition: a social contract for sustainability. Flagship Report. WBGU, Berlin. http://www.wbgu.de/fileadmin/templates/datei en/veroeffentlichungen/hauptgutachten/jg2011/wbgu_jg201 1_en.pdf

Wiek A, Withycombe L, Redman CL (2011) Key competencies in sustainability: a reference framework for academic program development. Sustain Sci 6(2):203-218

Wilber K (2000) [1995] Sex, ecology, spirituality: the spirit of evolution, 2nd edn. Shambhala Publications, Boston

Wilber K (2007) Integral Spirituality. A Startling New Role for Religion in the Modern and Postmodern World. Integral Books, Boston \& London
Wittmayer JM, Schäpke N (2014) Action, research and participation: roles of researchers in sustainability transitions. Sustain Sci 9(4):483-496. https://doi.org/10.1007/s11625-014-0258-4

Wittmayer J, Backhaus J, Avelino F, Bel B, Strasser T, Kunze I, Zuijderwijk L (2019) Narratives of change: how social innovation initiatives construct social transformation. Futures 112:102433. https://doi.org/10.1016/j.futures.2019.06.005

Woiwode C (2012) Exploring new horizons: the nexus of climate change, urban development and spirituality. Int J Urban Sustain Dev 4(2):219-235. https://doi.org/10.1080/19463 138.2012.694820

Woiwode C (2016) Off the beaten Tracks: the neglected significance of interiority for sustainable urban development. Futures 84:82-97. https://doi.org/10.1016/j.futures.2016.10.002

Woiwode C (2020) Inner transformation for 21st century futures: the missing dimension in higher education. Environment 62(4):30 38. https://doi.org/10.1080/00139157.2020.1764299

Woiwode C, Woiwode N (2019) Practical spirituality and the contemporary city: awakening the transformative power for sustainable living. In: Giri AK (ed) Practical spirituality and human development: creative experiments for alternative futures. Simgapore, Palgrave Mcmillan, pp 129-151

Publisher's Note Springer Nature remains neutral with regard to jurisdictional claims in published maps and institutional affiliations. 